Article

\title{
Investigation on Component Separation and Structure Characterization of Medium-Low Temperature Coal Tar
}

\author{
Ning Zhao ${ }^{1}$, Dong Liu ${ }^{1, *}$, Hui Du ${ }^{2}$, Congcong Wang ${ }^{1}$, Fushan Wen ${ }^{1}$ and Nan Shi ${ }^{1}$ \\ 1 State Key Laboratory of Heavy Oil Processing, College of Chemical Engineering, China University of \\ Petroleum (East China), Qingdao 266580, China; zhaoning0411@163.com (N.Z.); fox533@163.com (C.W.); \\ fushanwen@upc.edu.cn (F.W.); shinan@upc.edu.cn (N.S.) \\ 2 College of Chemistry and Chemical Engineering, Qingdao University, Qingdao 266071, China; \\ duhui@qdu.edu.cn \\ * Correspondence: liudong@upc.edu.cn; Tel./Fax: +86-0532-869-8038
}

Received: 11 September 2019; Accepted: 12 October 2019; Published: 15 October 2019

\begin{abstract}
Two medium-low temperature coal tars (MLCTs) derived from the pyrolysis of low-grade bituminous coal were separated into 11 narrow fractions by true boiling distillation. The primary property and chemical composition analysis of MLCTs and their distillate narrow fractions were investigated at the macroscopic and molecular level by gas chromatography-mass spectrometer (GC-MS) and proton nuclear magnetic resonance $\left({ }^{1} \mathrm{H}\right.$ NMR). The two MLCTs show obvious characteristics of medium-low temperature coal tar, including a high $\mathrm{H} / \mathrm{C}$, high-oxygen and nitrogen, low-sulfur, low-density, and low viscosity. As the boiling point increases, the molecular weight of each distillate fraction increases continuously. Meanwhile, the yield of each distillate fraction increases gradually, except for the $270-300{ }^{\circ} \mathrm{C}$ distillate fractions. The oxygen content in the $170-230{ }^{\circ} \mathrm{C}$ distillate fractions is much higher than that of the other distillate fractions. The dominant groups of compounds in the MLCTs were saturates, aromatics, and resins, and the resin content was above $24.5 \mathrm{wt} \%$. The molecular composition of the below $170{ }^{\circ} \mathrm{C}$ fractions mainly consists of benzene, toluene, and xylene, and the main phenolic compounds in the $170-230{ }^{\circ} \mathrm{C}$ distillate fraction are low-rank phenols, such as phenol, cresol, and xylenol. Although the macroscopic properties of the MLCT-Z and MLCT-S were quite similar, the molecular composition, the group composition and hydrogen distribution in each MLCT and its narrow distillate fractions are still different. The present work has contributed to our present understanding of the composition of MLCTs and to the guiding of the efficient processing of MLCTs.
\end{abstract}

Keywords: medium-low temperature coal tar; narrow fractions; molecular level; true boiling distillation; GC-MS; ${ }^{1} \mathrm{H}$ NMR

\section{Introduction}

The main fossil fuels, petroleum, natural gas, and coal are not only important energy sources but also feedstock for the modern chemical industry [1]. However, with the decline of crude oil prices and the sharp fluctuations of global oil prices, there is an urgent need to find alternative energy sources and solutions [2]. China, as the biggest developing country in the world, has significant reserves of low-rank coal deposits [3]. Through pyrolysis technology, low-rank coal is converted into semi-coke, coal tar, and carbonized gas to realize the comprehensive utilization of resources [4]. As the only liquid by-product, medium-low temperature coal tar (MLCT) can provide abundant information about the medium-low temperature pyrolysis process [5]. Through the analysis of the molecular composition and structure of coal tar, the relationship between the product characteristics and process parameters 
is obtained, which is helpful to reveal the mechanism of coal pyrolysis [6]. MLCT is a complex mixture of olefins, alkanes, aromatics, and variable amounts of heteroatomic organic compounds containing sulfur, nitrogen, oxygen, and metals [7]. MLCT, which has no secondary cracking and aromatization, high content of aliphatic hydrocarbon and $<360{ }^{\circ} \mathrm{C}$ light fraction, substantial amounts of phenolic compounds, and a high $\mathrm{H} / \mathrm{C}$ molar ratio, is suitable for the application in hydrogenation technology for producing clean fuels and chemicals [8]. Nonetheless, due to its high content of resin, asphaltene, and heteroatomic compounds, this will become the focal precursor, leading to the deactivation of catalysts and pipeline blockage [9]. At present, the development of the processing technology of MLCT is limited by an insufficient understanding of its chemical composition and structure [10]. Therefore, accurate qualitative and quantitative analysis of the molecular composition of MLCT will not only provide a data basis for the utilization of MLCT but also contribute to the efficient conversion of MLCT.

In recent years, many researchers have used physical and chemical methods to study the chemical composition of coal tar [11-15]. In general, the properties of coal tar were considered comprehensively and the components of coal tar were characterized by various physicochemical analysis methods [16-18]. However, the methods of separation and characterization are quite different, according to different research purposes. The main methods for separating specific components and groups include distillation, solvent extraction, precipitation, complexing methods, liquid chromatography, liquid membrane extraction, supercritical fluid extraction, deep eutectic solvent extraction, ionic liquid extraction, column chromatography, and high-performance liquid chromatography [19-27]. Pan et al. [19] used true boiling point distillation to separate 17 distillation fractions from initial boiling point (IBP) to $400{ }^{\circ} \mathrm{C}$ at an interval of $20^{\circ} \mathrm{C}$ and distillate residues of the middle-temperature coal tar, then the narrow distillate fractions were analyzed by gas chromatography-mass spectrometer (GC-MS). High-precision real boiling distillation can effectively control the carbon number distribution of narrow fractions and make the target components more concentrated. Gai et al. [20] used ethanolamine $\left(\mathrm{C}_{2} \mathrm{H}_{7} \mathrm{NO}\right)$ to separate phenolic compounds from coal tar and found that hydrogen-bond interactions resulted in the separation of phenolic compounds in coal tar. Laredo et al. [23] tested the removal efficiency of seventeen ionic liquids (ILs) and found that the nitrogen compounds present in the gas oil feed for diesel fuel production were successfully attained by means of ILs. Long et al. [25] separated the middle-temperature coal tar into acidic, basic, and neutral fractions first by acid-base extraction, and then extrography was used to fractionate the neutral fraction of into six subfractions. The structure and composition of coal tar and its subfractions were analyzed by gas chromatography (GC), GC-MS, Fourier transform infrared (FT-IR) spectroscopy, X-ray diffraction (XRD), inductively coupled plasma (ICP), and nuclear magnetic resonance (NMR) [28-36]. GC is a common technique for analyzing hydrocarbon mixtures due to its efficient separation ability [28]. However, most heteroatom compounds cannot be eluted from the GC column due to their poor volatility. Chen et al. [29] characterized the molecular characterization of ketones in coal tar and its fractions by GC-MS. Li et al. [31] studied the differences in the organic groups before and after hydroprocessing by FT-IR. Ma et al. [33] determined the distribution of 21 microelements in different distillate oils by inductively coupled plasma optical emission spectrometer (ICP-OES), and the distribution of elements in the distilled fractions was also investigated. Liu et al. [36] used ${ }^{1} \mathrm{H}$ NMR and ${ }^{13} \mathrm{C}$ NMR to analyze the structure of low-temperature coal tar asphaltene and obtained the types and distributions of different hydrogen/carbon atoms.

MLCT has a large molecular mass, and the boiling point range is also wide. First, MLCT is separated into several narrow fractions according to the boiling point of the fraction. After that, the composition and structure of MLCT, including the basic properties, hydrocarbon group composition, and structural group composition, are analyzed by advanced analytical means. In this study, true boiling distillation was used to separate MLCT into 11 narrow fractions. The composition and molecular structure of full-range fractions and narrow fractions were analyzed by GC-MS and ${ }^{1} \mathrm{H}$ NMR. The physicochemical properties and chemical composition of MLCT and narrow fractions were investigated at the macroscopic and molecular levels, respectively. The research results, the chemical composition of medium-low temperature coal tar was investigated in-depth from the molecular 
level, which will provide theory and data foundation for the utilization of medium-low temperature coal tar, including the technology selection, catalyst design, process development, and optimization. Meanwhile, the molecular level simulation optimization of the production process, the molecular level blending, and optimization of oils and refinement management of processing processes will be realized through the molecular level characterization of medium-low temperature coal tar.

\section{Materials and Methods}

\subsection{Materials}

The two MLCT samples (denoted as MLCT-Z and MLCT-S) were obtained by pyrolysis of low-grade bituminous coal in northern Shaanxi, China. The temperature of the pyrolytic reaction varied from $650{ }^{\circ} \mathrm{C}$ to $850^{\circ} \mathrm{C}$. The typical properties of MLCT analyzed according to Chinese national standards are shown in Table 1.

Table 1. The typical properties of medium-low temperature coal tar (MLCT).

\begin{tabular}{|c|c|c|}
\hline Parameter & MLCT-Z & MLCT-S \\
\hline Density $\left(20^{\circ} \mathrm{C}, \mathrm{g} / \mathrm{ml}\right)$ & 1.032 & 1.038 \\
\hline Viscosity $\left(50^{\circ} \mathrm{C}, \mathrm{mm}^{2} / \mathrm{s}\right)$ & 57.21 & 58.98 \\
\hline molecular weight (wt.\%) & 203 & 187 \\
\hline toluene insoluble (wt.\%) & 0.32 & 0.27 \\
\hline quinoline insoluble (wt.\%) & 0.21 & 0.14 \\
\hline carbon residue (wt.\%) & 5.76 & 5.93 \\
\hline ash (wt.\%) & 0.038 & 0.042 \\
\hline \multicolumn{3}{|l|}{ elemental component (wt.\%) } \\
\hline $\mathrm{C}$ & 85.57 & 84.94 \\
\hline $\mathrm{H}$ & 9.55 & 9.30 \\
\hline $\mathrm{N}$ & 0.65 & 0.66 \\
\hline S & 0.12 & 0.14 \\
\hline $\mathrm{O}$ & 4.11 & 4.96 \\
\hline $\mathrm{H} / \mathrm{C}$ ratio & 1.339 & 1.314 \\
\hline \multicolumn{3}{|l|}{ metal content $(\mu \mathrm{g} / \mathrm{g})$} \\
\hline $\mathrm{Fe}$ & 59.41 & 55.02 \\
\hline $\mathrm{Ca}$ & 16.80 & 13.94 \\
\hline $\mathrm{Mg}$ & 13.62 & 2.34 \\
\hline $\mathrm{Al}$ & 21.13 & 20.90 \\
\hline $\mathrm{Cr}$ & 7.58 & 10.55 \\
\hline $\mathrm{Zn}$ & 4.64 & 0.83 \\
\hline Mn & 3.63 & 3.08 \\
\hline \multicolumn{3}{|l|}{ distillation range $\left({ }^{\circ} \mathrm{C}\right)$} \\
\hline IBP & 197 & 198 \\
\hline $10 \%$ & 246 & 238 \\
\hline $30 \%$ & 307 & 297 \\
\hline $50 \%$ & 350 & 348 \\
\hline $80 \%$ & 395 & 397 \\
\hline
\end{tabular}

\subsection{Narrow Fraction Distillation}

The MLCT samples were dehydrated by an automatic dehydration device. The water-free MLCT samples were used for subsequent tests and analyses. All the distillation experiments were carried out on a true boiling point distillation instrument (German i-Fischer) equipped with a 20L distiller, a column with 15 theoretical plates and a reflux ratio of 10:1. The whole fraction of MLCT was separated into 11 narrow fractions containing IBP-170 ${ }^{\circ} \mathrm{C}, 170-190{ }^{\circ} \mathrm{C}, 190-210{ }^{\circ} \mathrm{C}, 210-230{ }^{\circ} \mathrm{C}, 230-250{ }^{\circ} \mathrm{C}$, $250-270{ }^{\circ} \mathrm{C}, 270-300{ }^{\circ} \mathrm{C}, 300-320^{\circ} \mathrm{C}, 320-340{ }^{\circ} \mathrm{C}, 340-360{ }^{\circ} \mathrm{C}$, and $>360^{\circ} \mathrm{C}$. The IBP-190 ${ }^{\circ} \mathrm{C}, 190-270{ }^{\circ} \mathrm{C}$, and $270-360^{\circ} \mathrm{C}$ distillate fractions were collected at atmospheric pressure, under a vacuum with a pressure of $100 \mathrm{~mm} \mathrm{Hg}$ and $10 \mathrm{~mm} \mathrm{Hg}$, respectively. 


\subsection{GC-MS Analysis}

The GC-MS analysis was carried out on an Agilent 7890A-5975C GC-MS equipped with an HP-5 MS column $(30 \mathrm{~m} \times 0.25 \mathrm{~mm} \times 0.25 \mu \mathrm{m})$. The GC oven was held at $40^{\circ} \mathrm{C}$ for $5 \mathrm{~min}$, programmed to $300{ }^{\circ} \mathrm{C}$ at $3{ }^{\circ} \mathrm{C} / \mathrm{min}$, and then held constant at $300{ }^{\circ} \mathrm{C}$ for $15 \mathrm{~min}$. Both the injector and transfer line were held at $300^{\circ} \mathrm{C}$. Helium was used as a carrier gas at a flow rate of $1 \mathrm{~mL} / \mathrm{min}$. The MS ion source was set at $230^{\circ} \mathrm{C}$. The MS ionizing voltage was $70 \mathrm{eV}$, and the mass range was $35-550 \mathrm{Da}$ with a $0.5 \mathrm{~s}$ scan period.

\section{4. ${ }^{1} \mathrm{H}$ NMR Analysis}

A Bruker-AC $400 \mathrm{MHz}$ NMR spectrometer was used to analyze the ${ }^{1} \mathrm{H}$ NMR of the narrow distillate fractions. All the experiments were performed at $25^{\circ} \mathrm{C}$, and the experimental parameters were set as follows: The sample concentration was $10 \mathrm{mg} / \mathrm{mL}$. In addition, deuterated chloroform $\left(\mathrm{CDCl}_{3}\right)$ and tetramethylsilane (TMS) were used as the solvent and internal standard in the ${ }^{1} \mathrm{H} N M R$ spectra, respectively.

\subsection{Relative Average Molecular Weight Analysis}

The relative average molecular weight $(\mathrm{Mn})$ of the narrow distillate fraction was determined by KNAUER K-7000 vapor pressure osmometry (VPO) to distinguish the composition of the narrow distillate fractions.

\subsection{Hydrocarbon-Group-Type Analysis}

Hydrocarbon-group-type analysis was carried out on the Agilent 7890A-5975C GC-MS according to the Chinese national standard SH/T 0606-2005. The analysis process was as follows: First, the MLCT was separated into a diesel fraction $\left(<350^{\circ} \mathrm{C}\right.$ fraction) and a heavy oil fraction $\left(>350^{\circ} \mathrm{C}\right.$ fraction) by atmospheric distillation. Second, the diesel fraction $(0.1 \mathrm{ml})$ was separated into two fractions by a solid extraction column packed with $2 \mathrm{~g}$ silica gel. N-pentane and dichloromethane/alcohol (5:1, v/v) were used to elute saturates and aromatics, respectively. GC analysis was carried out on an Agilent 7890A equipped with a $0.25 \mathrm{~mm} \times 0.25 \mu \mathrm{m} \times 30 \mathrm{~m}$ silica capillary column and a flame ionization detector (FID). The GC injector and detector temperature were $300^{\circ} \mathrm{C}$ and $350{ }^{\circ} \mathrm{C}$, respectively. MS analysis was carried out on an Agilent 5975C equipped with a $0.25 \mathrm{~mm} \times 0.25 \mu \mathrm{m} \times 30 \mathrm{~m}$ silica capillary column. The oven was kept at $60^{\circ} \mathrm{C}$ for $2 \mathrm{~min}$, programmed to $300^{\circ} \mathrm{C}$ at a rate of $40^{\circ} \mathrm{C} / \mathrm{min}$, and then held constant for $5 \mathrm{~min}$. The transfer line temperature was $290^{\circ} \mathrm{C}$. The MS ionizing voltage was $70 \mathrm{eV}$, and the mass range was 50-300 Da with a $0.5 \mathrm{~s}$ scan period. Third, the heavy oil fraction $(0.1 \mathrm{~g})$ was separated into three fractions by a solid extraction column packed with $4 \mathrm{~g}$ of silica gel. N-hexane, dichloromethane, and alcohol/dichloromethane $(1: 1, \mathrm{v} / \mathrm{v})$ were used to elute saturates, aromatics and resin, respectively. A $0.25 \mathrm{~mm} \times 0.25 \mu \mathrm{m} \times 40 \mathrm{~m}$ silica capillary column was used to transfer the hydrocarbons into the MS. The GC injector temperature was $350{ }^{\circ} \mathrm{C}$, and the oven temperature was kept at $60^{\circ} \mathrm{C}$ for $2 \mathrm{~min}$, programmed to $350^{\circ} \mathrm{C}$ at a rate of $40^{\circ} \mathrm{C} / \mathrm{min}$, and then held constant for $5 \mathrm{~min}$. The transfer line temperature was at $340^{\circ} \mathrm{C}$. The MS ionizing voltage was $70 \mathrm{eV}$, and the mass range was 50-700 Da with a $0.5 \mathrm{~s}$ scan period. At last, the hydrocarbon-group-type of diesel fraction and heavy oil fraction were counted up by mass yield.

\section{Results and Discussions}

\subsection{Properties of the MLCTs and Their Narrow Distillate Fractions}

Table 1 shows the main properties of the MLCTs. The density of MLCT-Z and MLCT-S are $1.032 \mathrm{~g} / \mathrm{cm}^{3}$ and $1.038 \mathrm{~g} / \mathrm{cm}^{3}$ (after dehydration at $20^{\circ} \mathrm{C}$ ), the $\mathrm{H} / \mathrm{C}$ ratios are 1.339 and 1.314 , and the molecular weights are 203 and 187, respectively. It can be seen that they have a relatively high H/C ratio, low contents of the insoluble fraction, and a high content of oxygen and nitrogen. Meanwhile, the 
elements with higher content are $\mathrm{Fe}, \mathrm{Ca}$, and $\mathrm{Al}$, mainly exist in the form of different salts. Compounds containing oxygen are key characteristic components of MLCT, accounting for $4.11 \%$ and $4.96 \%$ of the MLCTs, and mainly exist in phenolic compounds. The chemical instability of the MLCTs is caused by heteroatomic compounds containing oxygen, nitrogen, and metal. Fortunately, the low sulfur is very favorable for the deep processing of coal tar. The initial boiling point and temperature of the $80 \%$ distillate of MLCT were relatively high, implying that heavy components still occupied a large proportion of the fraction. MLCT-Z and MLCT-S show obvious characteristics of medium- and low-temperature coal tars, such as a high $\mathrm{H} / \mathrm{C}$ ratio, low contents of sulfur and insoluble fractions, a low density, and a low viscosity, while the contents of ash and carbon residue are high.

Figures 1 and 2 show the yields and molecular weights of the narrow distillate fractions, respectively. Different compounds in MLCT have different boiling points, so that the distillate fractions can be separated according to their boiling points. Moreover, true boiling point distillation can effectively control the carbon number of compounds in each narrow distillate fraction. The total fraction of MLCT was fractionated into 11 distillate fractions. As the boiling point increases, the yield of each distillate fraction increases gradually, except for the $270-300{ }^{\circ} \mathrm{C}$ distillate fractions. With the boiling point temperature increasing from IBP- $170{ }^{\circ} \mathrm{C}$ to $>360^{\circ} \mathrm{C}$, the molecular weight of each distillate fraction increases continuously. In the same boiling range, the relative molecular mass of different MLCT fractions is different. According to the boiling point temperatures of MLCT-Z and MLCT-S, the yields are as follows: Naphtha fraction (IBP- $\left.170{ }^{\circ} \mathrm{C}\right) 1.15$ and $0.93 \mathrm{wt} \%$, phenol oil fractions $\left(170-230{ }^{\circ} \mathrm{C}\right.$ ) 8.36 and $11.45 \mathrm{wt} \%$, and diesel fraction $\left(230-360^{\circ} \mathrm{C}\right) 36.52$ and $35.86 \mathrm{wt} \%$. The yield of the $>360^{\circ} \mathrm{C}$ distillate fraction of MLCT-Z is $2.21 \%$ higher than that of MLCT-S, but the yield of the $170-230^{\circ} \mathrm{C}$ distillate fraction of the MLCT-Z is $3.09 \%$, which is relatively low. The $>360^{\circ} \mathrm{C}$ heavy distillate fraction (distillation residue) accounted for about half mass of the total MLCT, which belongs to coal tar pitch (mainly composed of polycyclic aromatic hydrocarbons), and was the main component of the MLCT. Researches $[7,8,36,37]$ have shown that the $>360^{\circ} \mathrm{C}$ heavy distillate fraction is exceedingly difficult to hydrogenate and has a low economic value.

Figure 3 shows the elemental composition analysis of the narrow distillate fractions. The elemental composition is the basic data reflecting the chemical essence of coal tar. The comparison between MLCT-Z and MLCT-S shows that there is no difference in the type of elements in the narrow fractions, and the variation trend of the elemental content is basically the same. Each narrow distillate fraction has a certain amount of nitrogen and sulfur. Hence, the full enrichment of nitrogen and sulfur in certain distillates was not reached through distillation. By contrast, the total heteroatom content of MLCT-Z is higher than that of MLCT-S. In particular, the difference in the nitrogen and oxygen contents is mainly due to the difference in coal properties and pyrolysis conditions.

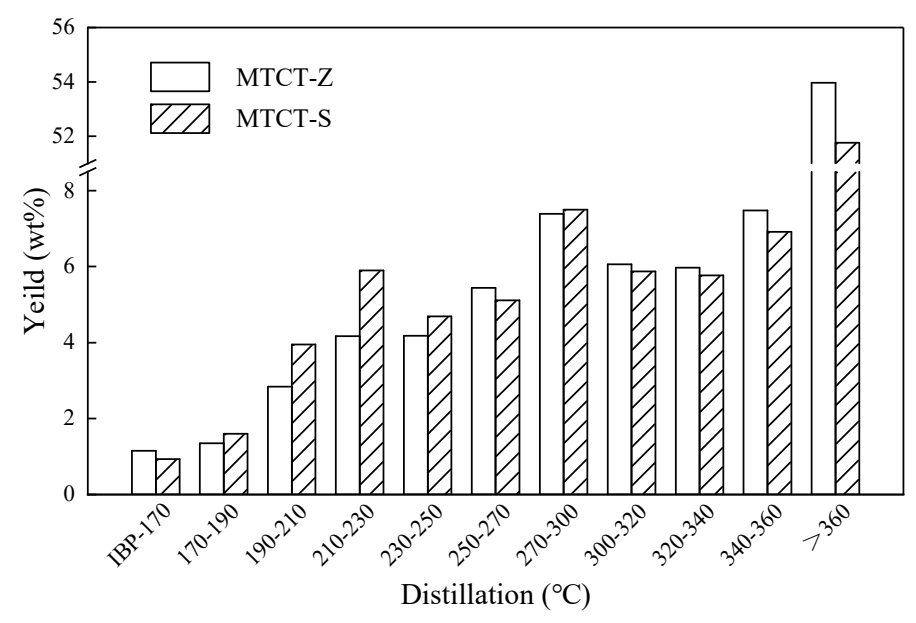

Figure 1. Yields of the distillates. 


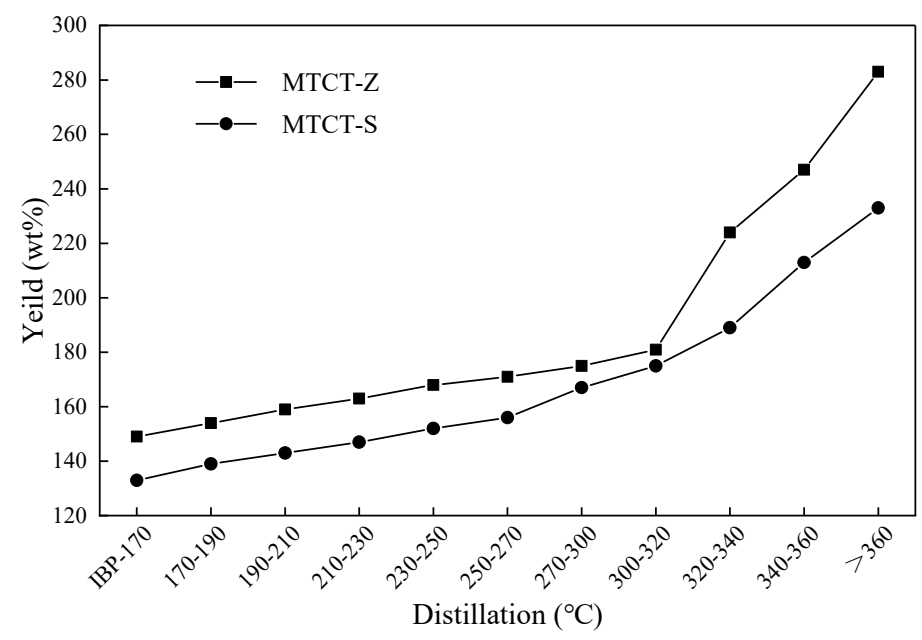

Figure 2. Molecular weight of the distillates.
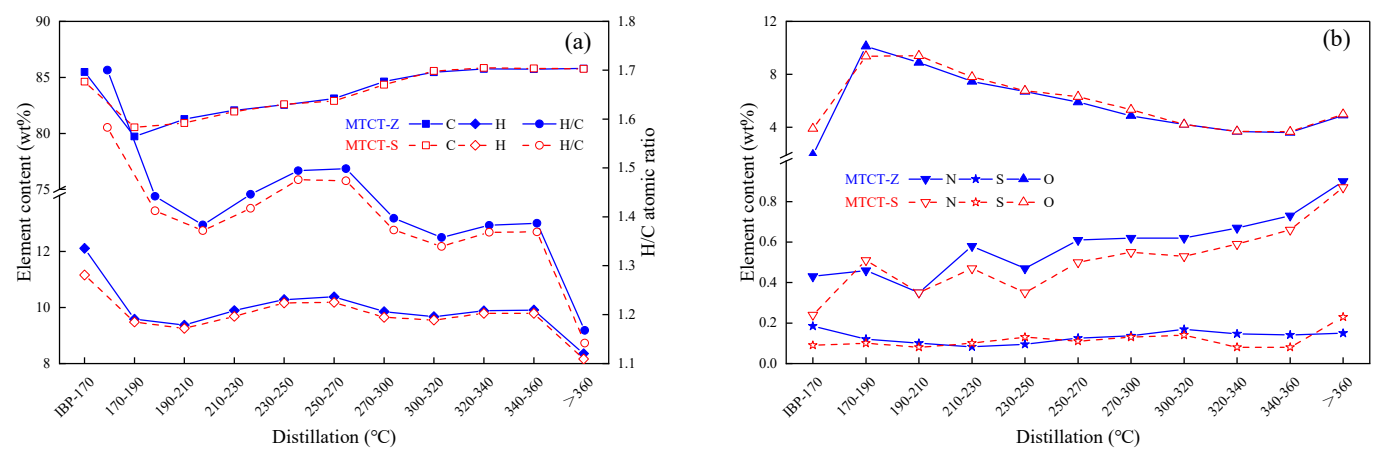

Figure 3. Element composition analysis for narrow distillate fractions of MLCT. (a) C, H, C/H, (b) N, $\mathrm{S}, \mathrm{O}$.

The $\mathrm{H} / \mathrm{C}$ atomic ratio is a vital parameter to characterize the average structure of coal tar, which is related to its chemical structure and molecular weight. It is obvious that, relative to the feedstock (Table 1), the $\mathrm{H} / \mathrm{C}$ atomic ratio of the $<360{ }^{\circ} \mathrm{C}$ distillate fractions increased, while that of the $>360{ }^{\circ} \mathrm{C}$ distillate fractions (1.17 and 1.14 ) decreased significantly. The oxygen contents in $170-190^{\circ} \mathrm{C}, 190-210^{\circ} \mathrm{C}$ and $210-230^{\circ} \mathrm{C}$ distillate fractions are much higher than those of the other distillate fractions, which is consistent with the fact that these fractions are rich in phenolic compounds.

\subsection{Hydrocarbon Type Analysis}

Table 2 shows the hydrocarbon type analysis of the MLCT. The results show that the MLCTs have three dominant groups of compounds: saturates, aromatics, and resins. The saturates are made up of paraffins and cycloalkanes, and the majority of the cycloalkane compounds are 1-3 ring cycloalkanes. The large amount of saturates is an important feature of MLCT. However, the amount of saturates is notably distinct. The total amount of alkanes and olefins is approximately $10 \mathrm{wt} \%$ and as high as $30 \mathrm{wt} \%$. By contrast, the content of saturates in MLCT-Z is $6.8 \%$ higher than that in MLCT-S. The paraffin and cycloalkane compounds could be used as a cracking feed. The aromatics are mainly composed of 1-5 aromatic-ring compounds and heteroatomic compounds such as sulfur compounds. The abundant aromatic compounds are mainly 1-3 aromatic-ring compounds with and without short side chains. The main monoaromatic hydrocarbons are alkylbenzenes and indans, followed byindenes. Naphthalenes, acenaphthenes, and acenaphthylenes account for more than $90 \%$ of the diaromatics. Meanwhile, the amount of monoaromatics in MLCT-Z is $10.6 \%$ less than that in MLCT-S. Although the two MLCT samples come from different production processes, the resin content is the same. As shown in Table 2, the resins content is $24.7 \mathrm{wt} \%$, which is almost $1 / 4$ of the raw MLCT material. 
In general, resins are the most complex and heaviest fraction of MLCTs. However, the research found that compared to resins from crude oils, the resins from MLCT have essential differences in chemical composition. The hydrocarbon type of MLCT largely determines the performance of MLCT and its products, therefore, the hydrocarbon type results can be used as an important basis for selecting a suitable processing technology.

Table 2. Hydrocarbon type analysis of the MLCT.

\begin{tabular}{ccc}
\hline \multirow{2}{*}{ Hydrocarbon Group Types } & \multicolumn{2}{c}{ Weight Percent (wt \%) } \\
\cline { 2 - 3 } & MLCT-Z & MLCT-S \\
\hline paraffins & 18.1 & 11.3 \\
1-ring cycloalkanes & 5.6 & 4.2 \\
2-ring cycloalkanes & 3.1 & 2.1 \\
3-ring cycloalkanes & 3.3 & 2.1 \\
4-ring cycloalkanes & 0.7 & 0.7 \\
total cycloalkanes & 12.7 & 9.1 \\
Total Saturates & 30.8 & 20.4 \\
alkylbenzenes & 4.7 & 9.7 \\
naphthenebenzenes & 0.7 & 0.6 \\
dinaphthenebenzenes & 0.8 & 0.7 \\
indans or tetralins & 4.6 & 6.0 \\
indenes & 3.4 & 7.9 \\
total monoaromatics & 14.2 & 24.9 \\
naphthalenes & 7.6 & 7.6 \\
acenaphthenes & 6.3 & 6.8 \\
acenaphthylenes & 3.5 & 4.2 \\
fluorenes & 1.5 & 1.3 \\
total diaromatics & 18.9 & 19.7 \\
total triaromatics & 5.5 & 5.2 \\
4-ring aromatics & 3.2 & 2.9 \\
5-ring aromatics & 0.7 & 0.6 \\
benzothiophenes & 0.7 & 0.6 \\
dibenzothiophenes & 0.2 & 0.2 \\
total sulfur compounds & 0.9 & 0.8 \\
unidentified aromatics & 1.1 & 1.0 \\
Total Aromatics & 44.5 & 55.3 \\
Resins & 24.7 & 24.5 \\
\hline
\end{tabular}

\subsection{Characterization of Narrow Distillate Fractions by GC-MS}

Figure 4 shows the GC-MS chromatograms of narrow distillate fractions obtained by true boiling distillation. Distillation is a very convenient method for separating and concentrating components of liquid fossil fuels. However, ordinary distillation methods are not suitable for the easy-coking and thermal sensitive materials in MLCT. True boiling distillation can be operated under vacuum pressure and helps minimize property changes. As shown in Figure 4, as the distillate boiling point temperature increases, the narrow distillate fractions become heavier, and the peak residence time changes from short to long. Compared with the full-range, the narrow distillate fractions have a simpler composition and a more concentrated carbon distribution. The overlap of adjacent components indicates that the components of MLCT cannot be separated completely by true boiling distillation.

The results show that phenols and alkylbenzenes are the main compounds in the distillate fractions below $170{ }^{\circ} \mathrm{C}$, especially phenol and BTX (benzene, toluene, and xylene) in the fractions below $170{ }^{\circ} \mathrm{C}$, the content of BTX in MLCT-Z is approximately $27.2 \%$, while the content of phenol in MLCT-S is approximately $33.6 \%$. The fractions below $170{ }^{\circ} \mathrm{C}$ are a suitable feedstock for chemical products rich in BTX aromatics. In the fractions of $170-230^{\circ} \mathrm{C}$, phenolic substances are dominant, and the content of phenols is more than $60 \%$. However, the other compounds, such as the homologs of benzene and naphthalene compounds are also present. The main phenolic compounds in the $170-230{ }^{\circ} \mathrm{C}$ distillate fraction are low-rank phenols, such as phenol, cresol, and xylenol. The higher-rank phenols (such as $\mathrm{C}_{3}-\mathrm{C}_{4}$ alkyl phenols), indenols, naphthols, and alkyl naphthols, are concentrated in fractions above $230^{\circ} \mathrm{C}$. Naphthalene is in the $190-210^{\circ} \mathrm{C}$ and $210-230^{\circ} \mathrm{C}$ distillate fractions, and its homologs are in 
the $230-250{ }^{\circ} \mathrm{C}$ and $250-270{ }^{\circ} \mathrm{C}$ distillate fractions. Fluorenes, dibenzofuran and octadecane are in the $270-300{ }^{\circ} \mathrm{C}$ distillate fractions. Alkyl fluorenes and alkyl naphthols, phenanthrene, nonadecane are in the $300-320^{\circ} \mathrm{C}$ distillate fractions. Phenanthrenes, eicosane, and heneicosane are in the $320-340{ }^{\circ} \mathrm{C}$ distillate fractions. Alkanes, pyrene, anthracene, phenanthrene, and its homologs are in the $340-360^{\circ} \mathrm{C}$ distillate fractions. The MLCT middle distillates $\left(170-230^{\circ} \mathrm{C}\right)$ are rich in phenols, which are the main raw chemical materials in the chemical industry and should be extracted from coal tar before hydrogenation. As is known, phenolic compounds generate water during the hydrotreating process. The generation of water will shorten the service life of catalysts and increase energy consumption and hydrogen consumption in the hydrogenation process, and equipment corrosion is a serious issue. Therefore, the removal of phenolic compounds before refining is not only beneficial to the hydrogenation process, but can also help to obtain abundant chemical materials.

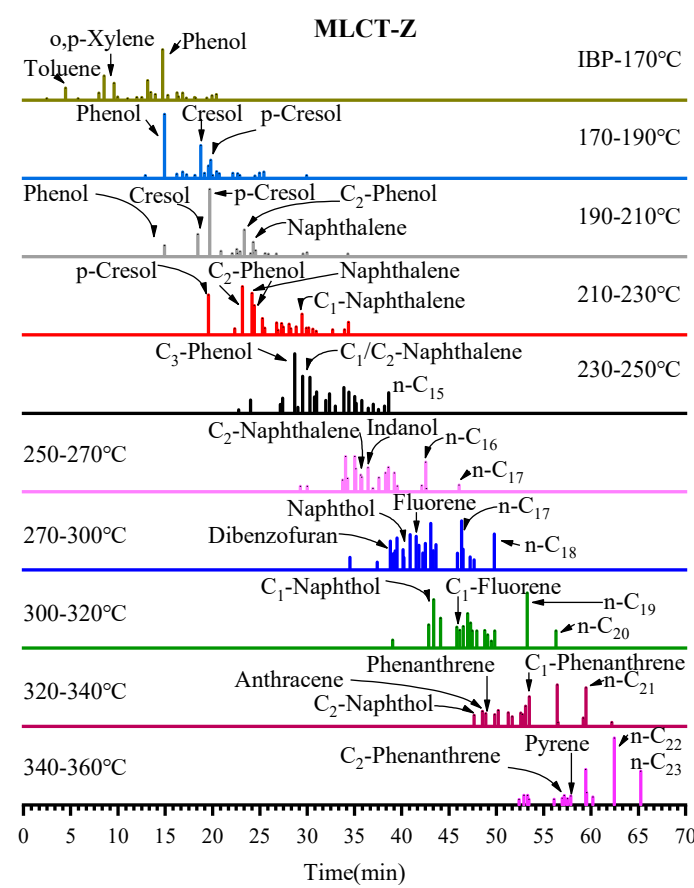

(a)

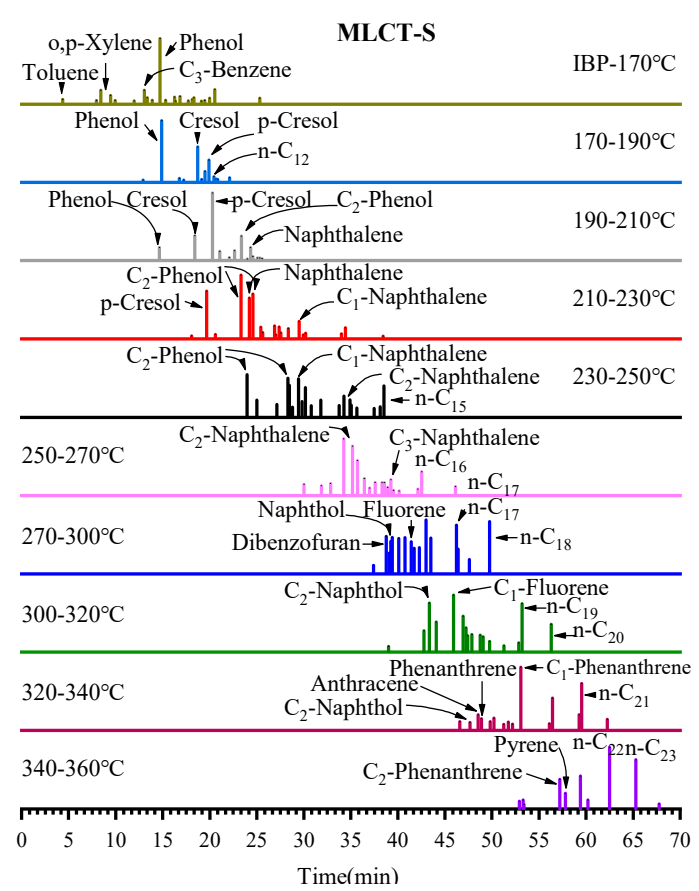

(b)

Figure 4. Gas chromatography-mass spectrometer (GC-MS) chromatograms of narrow distillate fractions. (a) The main components of narrow fractions from MLCT-Z; (b) The main components of narrow fractions from MLCT-S.

\subsection{Characterization of Narrow Distillate Fractions by ${ }^{1} \mathrm{H} N \mathrm{NR}$}

The main virtue of NMR analysis is its ability to associate resonances in specific chemical shift ranges with particular structural features. Based on this, the chemical shifts of hydrogen in the MLCT-Z and MLCT-S and their narrow fractions were measured by ${ }^{1} \mathrm{H}$ NMR. The division of the $\mathrm{H}_{\mathrm{Ar}}$ (Aromatic ring protons and aromatic ring hydroxyl, polynuclear aromatic hydrogen, $\delta=6.0-9.0), \mathrm{H}_{\alpha}\left(\alpha-\mathrm{CH}_{2}\right.$, $\alpha-\mathrm{CH}_{3}$ alkyl protons in aromatic rings, alcohols and mercaptan hydroge, $\left.\delta=2.0-4.0\right), \mathrm{H}_{\mathrm{N}}\left(-\mathrm{CH} / \mathrm{CH}_{2}\right.$ in cycloalkanes, normal alkanes and iso-alkanes, $\delta=1.4-2.0), \mathrm{H}_{\beta}\left(\beta-\mathrm{CH}_{2}, \beta-\mathrm{CH}_{3}\right.$ alkyl protons in aromatic ring, $\beta-\mathrm{CH}_{2}$ groups in longer alkyl chain, $\left.\delta=1.0-1.4\right), \mathrm{H}_{\gamma}\left(\gamma-\mathrm{CH}_{3}\right.$ in aromatic cyclic alkyl protons, cycloalkanes, and alkanes, $\delta=0.5-1.0$ ) regions of the ${ }^{1} \mathrm{H}$ NMR spectrum, as shown in Table 3 , provided qualitative and quantitative information about different types of hydrogen. Data were expressed as the mean of three separate calculations.

From the data in Table 3, it can be seen that the distribution of hydrogen in the MLCT-Z and its narrow fraction was approximately the same as that in the MLCT-S and its narrow fraction, and the components of the two kinds of coal tar were quite similar. With the increase of the distillation temperature, the variation of the hydrogen content in the MLCT-Z and MLCT-S distillates was 
inconsistent. Overall, the naphthenic hydrogen peak areas of the narrow fractions of the two coal tars were the lowest, indicating that the naphthenic structure components in the coal tar samples were relatively small. The fractions with the highest $\mathrm{H}_{\mathrm{N}}$ content of MLCT- $\mathrm{Z}$ and MLCT-S were greater than $360{ }^{\circ} \mathrm{C}$ and $340-360{ }^{\circ} \mathrm{C}$, respectively, indicating that $\mathrm{H}_{\mathrm{N}}$ had different distillation ranges in different coal tars. In contrast, the $\mathrm{H}_{\alpha}$ content was the most in the fractions within the range of $210-250{ }^{\circ} \mathrm{C}$, manifesting that there were more methyl ethyl benzenes in this segment in the form of $\alpha-\mathrm{CH}_{2}$ alkyl protons and $\alpha-\mathrm{CH}_{3}$ alkyl protons. Compared to the peak areas of different hydrogen in the narrow fraction of each coal tar, it was found that the fractions with IBP- $170{ }^{\circ} \mathrm{C}$ and above $300{ }^{\circ} \mathrm{C}$ in the distillation range contain more $\mathrm{H}_{\beta}$, showing that a high amount of hydrogen in the $\beta$ or further positions of the aromatic ring were in the form of $\mathrm{CH}_{2}$ and $-\mathrm{CH}-$, or in the form of $-\mathrm{CH}$ - attached to methyl groups. The data showed that the $\mathrm{H}_{\beta}$ content of the MLCT- $Z$ was much higher than that of the MLCT-S when the distillation range was $340-360^{\circ} \mathrm{C}$. Combined with the results of GC-MS analysis, the contents of long-chain alkanes and methyl phenols of this narrow fraction in MLCT-Z were higher than those of MLCT-S. The fraction of $170-210{ }^{\circ} \mathrm{C}$ in the distillation range was mainly composed of $\mathrm{H}_{\mathrm{Ar}}$, indicating that there were more components with an aromatic ring structure. Combined with the results of element analysis, it was found that the $\mathrm{O}$ content in this segment was relatively high, which proved that this narrow fraction was mainly composed of phenolic compounds such as methyl phenol and dimethyl phenol. It was reported that the boiling range of phenol oil was $170-210^{\circ} \mathrm{C}$, which proved the reliability of the ${ }^{1} \mathrm{HNMR}$ analysis of coal tar. However, $\mathrm{H}_{\mathrm{Ar}}$ had the largest peak area, and the degree of branching was smaller than the other narrow fractions in the two coal tar distillates, the distillation range of which was higher than $340^{\circ} \mathrm{C}$, which meant that there were fewer alkyl side chains in its components, but polycyclic aromatic compounds were the main components. As shown in Figure 2, the higher molecular weight of the distillation range above $340{ }^{\circ} \mathrm{C}$ indicated that $\mathrm{H}$ in this narrow fraction was mainly polycyclic aromatic hydrogen and existed in the form of polycyclic aromatic compounds, while the polycyclic aromatic compounds of MLCT-Z were mainly concentrated in the distillation range greater than $360{ }^{\circ} \mathrm{C}$ fractions. The significant difference in the $\mathrm{H}$ distribution of the narrow fractions of MLCT- $Z$ and MLCT-S was mainly reflected in the content of $\mathrm{H}_{\beta}, \mathrm{H}_{\gamma}$, and $\mathrm{H}_{\mathrm{Ar}}$ in the distillates above $360^{\circ} \mathrm{C}$. The experimental results indicated that the chemical composition of heavy oil in the MLCT-Z and the MLCT-S was still very different.

Table 3. Hydrogen types in distillate from MLCT-Z and MLCT-S.

\begin{tabular}{|c|c|c|c|c|c|c|c|c|c|c|}
\hline \multirow{2}{*}{$\begin{array}{l}\text { Distilling } \\
\text { Range/ } /{ }^{\circ} \mathrm{C}\end{array}$} & \multicolumn{2}{|c|}{$\mathrm{H}_{\mathrm{A}}(\delta=10.0-6.0)$} & \multicolumn{2}{|c|}{$\mathrm{H}_{\alpha}(\delta=2.0-24.0)$} & \multicolumn{2}{|c|}{$\mathrm{H}_{\beta}(\delta=1.0-21.4)$} & \multicolumn{2}{|c|}{$\mathrm{H}_{\gamma}(\delta=0.5-21.0)$} & \multicolumn{2}{|c|}{$H_{n}(\delta=1.4-2.0)$} \\
\hline & MLCT-Z & MLCT-S & MLCT-Z & MLCT-S & MLCT-Z & MLCT-S & MLCT-Z & MLCT-S & MLCT-Z & MLCT-S \\
\hline full range & 17.47 & 13.69 & 18.43 & 17.00 & 41.84 & 46.25 & 13.63 & 15.56 & 8.64 & 7.49 \\
\hline IBP-170 & 16.03 & 20.28 & 17.47 & 16.84 & 34.29 & 29.82 & 21.47 & 18.46 & 10.74 & 14.60 \\
\hline 170-190 & 37.84 & 38.17 & 21.62 & 20.61 & 22.39 & 22.90 & 11.58 & 11.45 & 6.56 & 6.87 \\
\hline $190-210$ & 34.25 & 35.34 & 31.16 & 32.51 & 19.86 & 18.37 & 8.90 & 8.48 & 5.82 & 5.30 \\
\hline $210-230$ & 26.95 & 28.99 & 36.39 & 36.81 & 22.64 & 20.58 & 8.89 & 8.70 & 5.12 & 4.93 \\
\hline $230-250$ & 22.22 & 23.81 & 31.56 & 31.67 & 26.00 & 24.76 & 12.22 & 11.43 & 8.00 & 8.33 \\
\hline $250-270$ & 15.80 & 22.62 & 26.07 & 31.11 & 24.64 & 26.48 & 26.22 & 11.31 & 7.27 & 8.48 \\
\hline $270-300$ & 21.84 & 21.79 & 24.60 & 29.41 & 33.33 & 29.19 & 13.56 & 11.33 & 6.67 & 8.28 \\
\hline $300-320$ & 21.93 & 24.57 & 24.56 & 25.80 & 33.33 & 30.47 & 13.60 & 12.29 & 6.58 & 6.88 \\
\hline $320-340$ & 24.00 & 23.36 & 21.36 & 23.13 & 34.85 & 34.35 & 14.77 & 13.32 & 5.02 & 5.84 \\
\hline $340-360$ & 15.36 & 45.66 & 55.31 & 19.18 & 11.54 & 14.16 & 9.31 & 5.94 & 8.48 & 15.07 \\
\hline$>360$ & 42.52 & 22.99 & 20.09 & 20.69 & 17.29 & 39.77 & 7.01 & 9.89 & 13.08 & 6.67 \\
\hline
\end{tabular}

\section{Conclusions}

The two MLCTs derived from the pyrolysis of low-grade bituminous coal, which had a high H/C ratio, high-oxygen and nitrogen, low-sulfur, low density and low viscosity, show obvious characteristics of medium-low temperature coal tar. The fractions below $170{ }^{\circ} \mathrm{C}$, mainly consisting of benzene, toluene, and xylene, are suitable feedstock for chemical products rich in BTX aromatics. The $170-230{ }^{\circ} \mathrm{C}$ distillate fractions of MLCT have high oxygen content and are rich in phenols, which are the main raw chemical materials in the chemical industry and should be extracted from coal tar before hydrogenation. The $>360^{\circ} \mathrm{C}$ heavy distillate fraction, which belongs to coal tar pitch, accounted for about half of 
the total mass, is exceedingly difficult to hydrogenate, and has a low economic value. Although the macroscopic properties of the MLCT-Z and MLCT-S are quite similar, the molecular composition, group composition, and hydrogen distribution in each MLCT and their narrow distillate fractions are still different.

Author Contributions: Data curation, N.Z. and C.W.; formal analysis, N.Z. and N.S.; methodology, N.Z. and F.W.; writing—original draft, N.Z.; writing—review \& editing, D.L. and H.D.

Funding: This research was funded by the National Key Research and Development Program (2018YFC1801901), Fundamental Research Funds for the Central Universities (18CX05024A, 18CX06062A, 17CX05016), as well as the China Postdoctoral Science Foundation (2019T120571, 2018M632623).

Conflicts of Interest: The authors declare no conflict of interest.

\section{References}

1. Olah, G.A.; Goeppert, A.; Prakash, G.K.S. Beyond oil and gas: The methanol economy. Am. J. Plant Physiol. 2007, 164, 525-526.

2. Cui, W.G.; Li, W.H.; Gao, R.; Ma, H.; Li, D.; Niu, M.L.; Lei, X. Hydroprocessing of low-temperature coal tar for the production of clean fuel over fluorinated NiW/Al2O3-SiO2 catalyst. Energy Fuels 2017, 31, 3768-3783. [CrossRef]

3. Yan, J.; Bai, Z.; Bai, J.; Guo, Z.; Li, W. Effects of organic solvent treatment on the chemical structure and pyrolysis reactivity of brown coal. Fuel 2014, 128, 39-45. [CrossRef]

4. Xue, F.; Li, D.; Guo, Y.; Liu, X.; Ma, B. Technical progress and prospect of low rank coal pyrolysis in china. Energy Technol. 2017, 5, 1897-1907. [CrossRef]

5. Gao, Z.; Zheng, M.; Zhang, D.; Zhang, W. Low temperature pyrolysis properties and kinetics of non-coking coal in Chinese western coals. J. Energy Inst. 2016, 89, 544-559. [CrossRef]

6. Sun, M.; Ma, M.M.; Lv, B.; Yao, J.W.; Wang, R.C.; Zhang, Y.J.; Mao, X.X. Pyrolysis characteristics of ethanol swelling Shendong coal and the composition distribution of its coal tar. J. Anal. Appl. Pyrolysis 2019, 138, 94-102. [CrossRef]

7. Li, D.; Li, Z.; Li, W.; Liu, Q.; Feng, Z.; Fan, Z. Hydrotreating of low temperature coal tar to produce clean liquid fuels. J. Anal. Appl. Pyrolysis 2013, 100, 245-252. [CrossRef]

8. Yuan, Y.; Li, D.; Zhang, L.; Zhu, Y.; Wang, L.; Li, W. Development, status, and prospects of coal tar hydrogenation technology. Energy Technol. 2016, 4, 1-12. [CrossRef]

9. Sun, J.; Li, D.; Yao, R.; Sun, Z.; Li, X.; Li, W. Modeling the hydrotreatment of full range medium temperature coal tar by using a lumping kinetic approach. React. Kinet. Catal. Lett. 2015, 114, 451-471. [CrossRef]

10. Zuo, P.P.; Qu, S.J.; Shen, W.Z. Asphaltenes: Separations, structural analysis and applications. J. Energy Chem. 2018, 34, 186-207. [CrossRef]

11. Ni, H.X.; Xu, C.M.; Wang, R.; Guo, X.F.; Long, Y.H.; Ma, C.; Yan, L.L.; Liu, X.X.; Shi, Q. Composition and transformation of sulfur-, oxygen-, and nitrogen-containing compounds in the hydrotreating process of a low temperature coal tar. Energy Fuels 2018, 32, 3077-3084. [CrossRef]

12. Zhang, L.; Xu, D.; Gao, J.; Zhou, S.; Zhao, L.; Zhang, Z. Extraction and mechanism for the separation of neutral N-compounds from coal tar by ionic liquids. Fuel 2017, 194, 27-35. [CrossRef]

13. Cao, X.; Peng, B.; Ma, S.T.; Ni, H.X.; Zhang, L.Z.; Zhang, W.L.; Li, M.Y.; Hsu, C.S.; Shi, Q. Molecular selectivity in supercritical $\mathrm{CO}_{2}$ extraction of a crude oil. Energy Fuels 2017, 31, 4996-5002. [CrossRef]

14. Wang, X.L.; Shen, J.; Niu, Y.X.; Sheng, Q.T.; Liu, G.; Wang, Y.G. Solvent extracting coal gasification tar residue and the extracts characterization. J. Clean. Prod. 2016, 133, 965-970. [CrossRef]

15. Wang, Y.G.; Jiang, G.C.; Zhang, S.J.; Zhang, H.Y.; Lin, X.C.; Huang, X.; Fan, M.H. The application of a modified dissolving model to the separation of major components in low-temperature coal tar. Fuel Process. Technol. 2016, 149, 313-319. [CrossRef]

16. Shi, Q.; Zhao, S.; Xu, Z.; Chung, K.H.; Zhang, Y.; Xu, C. Distribution of acids and neutral nitrogen compounds in a Chinese crude oil and its fractions: Characterized by negative-ion electrospray ionization Fourier transform ion cyclotron resonance mass spectrometry. Energy Fuels 2010, 24, 4005-4011. [CrossRef]

17. Liu, F.J.; Fan, M.; Wei, X.Y.; Zong, Z.M. Application of mass spectrometry in the characterization of chemicals in coal-derived liquids. Mass Spectrom. Rev. 2016, 36, 543-579. [CrossRef] 
18. Sun, M.; Zhang, D.; Yao, Q.X.; Li, Y.Q.; Sun, X.P.; Jia, C.Q. Separation and composition analysis of gc/ms analyzable and unanalyzable parts from coal tar. Energy Fuels 2018, 32, 7404-7411. [CrossRef]

19. Pan, Y.; Yang, B.; Zhou, X. Feedstock molecular reconstruction for secondary reactions of fluid catalytic cracking gasoline by maximum information entropy method. Chem. Eng. J. 2015, 281, 945-952. [CrossRef]

20. Ding, Y.H.; Chen, H.; Wang, D.F.; Ma, W.G.; Wang, J.F.; Xu, D.P.; Wang, Y.G. Supercritical fluid extraction and fractionation of high-temperature coal tar. J. Fuel Chem. Technol. 2010, 38, 140-143. [CrossRef]

21. Gai, H.; Qiao, L.; Zhong, C.; Zhang, X.; Xiao, M.; Song, H. A solvent based separation method for phenolic compounds from low-temperature coal tar. J. Clean. Prod. 2019, 223, 1-11. [CrossRef]

22. Pei, L.J.; Li, D.; Liu, X.; Cui, W.G.; Shao, R.T.; Xue, F.F.; Li, W.H. Investigation on asphaltenes structures during low temperature coal tar hydrotreatment under various reaction temperatures. Energy Fuels 2017, 31 , 4705-4713. [CrossRef]

23. Laredo, G.C.; Likhanova, N.V.; Lijanova, I.V.; Rodrigue-Zheredia, B.J.; Jesús Castillo, J.; Perez-Romo, P. Synthesis of ionic liquids and their use for extracting nitrogen compounds from gas oil feeds towards diesel fuel production. Fuel Process. Technol. 2015, 130, 38-45. [CrossRef]

24. Jiao, T.; Li, C.; Zhuang, X.; Cao, S.; Chen, H.; Zhang, S. The new liquid-liquid extraction method for separation of phenolic compounds from coal tar. Chem. Eng. J. 2015, 266, 148-155. [CrossRef]

25. Long, H.; Shi, Q.; Pan, N.; Zhang, Y.; Cui, D.; Chung, K.H. Characterization of middle-temperature gasification coal tar. part 2: Neutral fraction by extrography followed by gas chromatography-mass spectrometry and electrospray ionization coupled with Fourier transform ion cyclotron resonance mass spectrometry. Energy Fuels 2012, 26, 3424-3431. [CrossRef]

26. Pang, K.; Hou, Y.; Wu, W.; Guo, W.; Peng, W.; Marsh, K.N. Efficient separation of phenols from oils via forming deep eutectic solvents. Green Chem. 2012, 14, 2398-2401. [CrossRef]

27. Sun, M.; Ma, X.X.; Yao, Q.X.; Wang, R.C.; Ma, Y.X.; Feng, G.; Shang, J.X.; Xu, L.; Yang, Y.H. GC-MS and TG-FTIR Study of Petroleum Ether Extract and Residue from Low Temperature Coal Tar. Energy Fuels 2011, 25, 1140-1145. [CrossRef]

28. Ma, S.; Ma, C.; Qian, K.; Zhou, Y.; Shi, Q. Characterization of phenolic compounds in coal tar by gas chromatography/negative-ion atmospheric pressure chemical ionization mass spectrometry. Rapid Commun. Mass Spectrom. 2016, 30, 1806-1810. [CrossRef]

29. Chen, X.; Xu, C.; Zhang, W.; Ma, C.; Liu, X.; Zhao, S.; Shi, Q. Separation and molecular characterization of ketones in a low temperature coal tar. Energy Fuels 2018, 32, 4662-4670. [CrossRef]

30. Wu, Y.; Yan, B.; Zhao, Y.; Hu, F. Structural characterization of coal tar pitch aromatic component based on molecular weight. J. China Coal Soc. 2018, 43, 3226-3231.

31. Li, D.; Cui, W.; Zhang, X.; Meng, Q.; Zhou, Q.; Ma, B.; Niu, M.; Li, W. Production of clean fuels by catalytic hydrotreating a low temperature coal tar distillate in a pilot-scale reactor. Energy Fuels 2017, 31, 11495-11508. [CrossRef]

32. Xu, C.; Liu, Y.; Zhao, S.; Shi, Q. Compositional analysis of petroleum asphaltenes by negative ion electrospray high resolution FT-ICR mass spectrometry. J. China Univ. Pet. 2013, 37, 190-195.

33. Ma, M.; Su, X.; Min, X.; Zheng, H.; Fan, Y.; Wan, C.; Sun, M.; Ma, X. Migration law of metal elements during distillation of low temperature coal tar. Chem. Ind. Eng. Prog. 2018, 37, 3355-3361.

34. Poveda, J.C.; Molina, D.R. Average molecular parameters of heavy crude oils and their fractions using NMR spectroscopy. J. Pet. Sci. Eng. 2012, 84, 1-7. [CrossRef]

35. López, D.; Acelas, N.; Mondragón, F. Average structural analysis of tar obtained from pyrolysis of wood. Bioresour. Technol. 2010, 101, 2458-2465. [CrossRef]

36. Liu, X.; Li, D.; Yang, Z.; Wang, S.; Pei, L.; Shao, R.; Niu, M.L.; Li, W.L. Investigation on the structure of low-temperature coal tar asphaltene precipitated with different n-alkane solvents. Energy Sources Part $A$ 2018, 40, 1226-1233. [CrossRef]

37. Niu, M.L.; Sun, X.; Li, D.; Cui, W.; Zhang, X.; Bai, X.; Li, W.L. The hydrodeoxygenation, hydrogenation, hydrodealkylation and ring-opening reaction in the hydrotreating of low temperature coal tar over $\mathrm{Ni}-\mathrm{Mo} / \gamma-\mathrm{Al}_{2} \mathrm{O}_{3}$ catalyst. Reac. Kinet. Mech. Catal. 2017, 121, 487-503. [CrossRef]

(C) 2019 by the authors. Licensee MDPI, Basel, Switzerland. This article is an open access article distributed under the terms and conditions of the Creative Commons Attribution (CC BY) license (http://creativecommons.org/licenses/by/4.0/). 